\title{
Analgesic Activities of Synthesized Divalent Metal Complexes of Tolfenamic Acid
}

\author{
Md. Mahabob Ullah Mazumder ${ }^{1}$, Abhijit Sukul ${ }^{2}$ and Sajal Kumar Saha ${ }^{1}$ \\ ${ }^{1}$ Department of Clinical Pharmacy and Pharmacology, Faculty of Pharmacy, University of Dhaka, \\ Dhaka-1000, Bangladesh \\ ${ }^{2}$ Department of Pharmacy, Faculty of Health Sciences, Northern University Bangladesh, \\ Dhaka-1215, Bangladesh
}

Received: May 11, 2015; Accepted: June 14, 2016; Published (web): June 20, 2016

\begin{abstract}
The objective of the study was to synthesize and to uncover the potentially interesting biological peripheral and central analgesic activities of some new divalent metal complexes of tolfenamic acid. The inception of the study was carried out with the formation of complexes $\left[\mathrm{Cu}(\text { tolf })_{2}\left(\mathrm{H}_{2} \mathrm{O}\right)\right]_{2}$, $\left[\mathrm{Co}(\text { tolf })_{2}\left(\mathrm{H}_{2} \mathrm{O}\right)_{2}\right]$ and $\left[\mathrm{Zn}(\text { tolf })_{2}\left(\mathrm{H}_{2} \mathrm{O}\right)\right]$ through the reaction of tolfenamic acid, a potent anti-inflammatory drug, with $\mathrm{Cu}$, $\mathrm{Co}$ and $\mathrm{Zn}$ salts. Characterization of the metal complexes of tolfenamic acid was furnished with spectral (FTIR, UV-Visible) and calorimetric (DSC) analysis. The peripheral analgesic activities of the complexes were investigated by acetic acid-induced writhing method. In peripheral analgesia model, $\mathrm{Cu}, \mathrm{Co}$ and $\mathrm{Zn}$ complexes of tolfenamic acid showed significantly promising analgesic potency at a dose of $25 \mathrm{mg} / \mathrm{kg}$ body weight with percentage of inhibition of acetic acid induced writhing by $49.67 \%$ $(\mathrm{p}<0.01), 67.32 \%(\mathrm{p}<0.001)$ and $72.55 \%(\mathrm{p}<0.001)$, respectively compared to the standard tolfenamic acid $46.41 \%$. Radiant heat tail-flick test was used to observe the central analgesic activity which showed analgesic effect evidenced by $\%$ elongation time $(34.59 \%, 25.34 \%$ and $53.08 \%$ ), respectively compared to that of morphine $2 \mathrm{mg} / \mathrm{kg}$ body weight at an equimolar dose of tolfenamic acid at $10 \mathrm{mg} / \mathrm{kg}$ body weight after 30 minutes. In the final analysis, it can be stipulated that newly synthesized stable metal complexes of tolfenamic acid have promising pharmacological effects like peripheral and central analgesic potency. Therefore, these complexes may be the better therapeutic options in the near future however it needs further extensive analysis in the pharmacokinetics, pharmacodynamics and toxicology perspective.
\end{abstract}

Key words: Tolfenamic acid, metal complex, characterization and analgesic activity.

\section{INTRODUCTION}

Non-steroidal anti-inflammatory drugs (NSAIDs) are also known as non-steroidal antiinflammatory agents/analgesics (NSAIAs) or nonsteroidal anti-inflammatory medicines (NSAIMs). These drugs have proved to be effective in the treatment of acute and chronic painful and inflammatory musculoskeletal conditions. ${ }^{1}$

Tolfenamic acid i.e., 2-[bis (3-chloro-2-methylphenyl)-amino] benzoic acid or Htolf is a potent, well-tolerated NSAID with anti-inflammatory, analgesic and antipyretic effects.

Correspondence to: Sajal Kumar Saha

Tel: +880-1720-579559; Email: sajal@du.ac.bd

Dhaka Univ. J. Pharm. Sci. 15(1): 89-96, 2016 (June)<smiles>Cc1c(Cl)cccc1Nc1ccccc1C(=O)O</smiles>

Tolfenamic acid

Tolfenamic acid acts by inhibiting prostaglandin and leukotriene synthesis. It is used to treat the symptoms of migraine. Chemically, it resembles mefenamic and flufenamic acids, other fenamates in clinical use. Tolfenamic acid inhibits COX-2 pathway preferentially. ${ }^{2}$ Transition metals have an important place within medicinal biochemistry. Many 
researchers have shown significant progress in utilization of transition metal complexes as drugs to treat several human diseases like carcinomas, lymphomas, infection, inflammation, diabetes and neurological disorders. Transition metals exhibit different oxidation states and can interact with a number of negatively charged molecules. This activity of transition metals has started the development of metal-based drugs with promising pharmacological application and may offer unique therapeutic opportunities. ${ }^{3}$ Metal-based drug is a research area of increasing interest for inorganic pharmaceutical and medicinal chemistry and has concentrated much attention as an approach to new drug development.

Recent studies revealed that, in addition to arthritis and pain, cancer and neurodegenerative diseases like Alzheimer's disease could potentially be treated with COX-2 inhibitors. Tolfenamic acid selectively inhibits COX-2 pathway to exert its antiinflammatory, analgesic and antipyretic effects.

The undertaken study was focused on the synthesis of some novel metal complexes $(\mathrm{Cu}, \mathrm{Co}$ and $\mathrm{Zn}$ complexes) of tolfenamic acid to screen better pharmacological profile compared to parent drug and also to investigate peripheral and central analgesic activities of metal complexes of tolfenamic acid.

\section{MATERIALS AND METHODS}

Drugs and materials. Tolfenamic acid was obtained from Eskayef Bangladesh Limited. Chemical salts of highest purity were collected from Advanced Chemical Industries Limited. Morphine was purchased from Popular Pharmaceuticals Ltd. Vincristine sulfate and ciprofloxacin were collected from Square Pharmaceuticals Ltd., Bangladesh.

Solvents and reagents. Dimethyl sulfoxide and sodium bicarbonate were purchased from Merck, Darmstadt, Germany. Acetone, Tween-80, methanol and 1, 1-dipheny-1-2-picryl hydrazyl were collected from Sigma Chemicals, USA. Normal saline was obtained from Opsonin Pharma Ltd. All chemicals and reagents were of analytical grade.
Synthesis of metal complexes. To a solution of tolfenamic acid $(0.262 \mathrm{~g}, 1 \mathrm{mmol})$ in methanol $(5 \mathrm{ml})$ was added a solution of $\mathrm{CuSO}_{4} .5 \mathrm{H}_{2} \mathrm{O}(0.249 \mathrm{~g}, 1$ mmol) in methanol. Drops of sodium methanoate (MeONa) were added till the apparent $\mathrm{pH}$ value was 7. The reaction mixture was stirred at room temperature for $2 \mathrm{~h} \&$ cooled to $5^{\circ} \mathrm{C}$ in a refrigerator for $4 \mathrm{~h}$. The precipitate was collected by filtration, washed with a mixture of $\mathrm{H}_{2} \mathrm{O}: \mathrm{MeOH}$ (1:5) \& dried in a vacuum to afford $\left[\mathrm{Cu}(\text { tolf })_{2}\left(\mathrm{H}_{2} \mathrm{O}\right)\right]_{2}$. A solution of $\mathrm{CoCl}_{2} .6 \mathrm{H}_{2} \mathrm{O}(0.095 \mathrm{~g}, 0.4 \mathrm{mmol})$ in $\mathrm{MeOH}(5 \mathrm{ml})$ and a solution of $\mathrm{ZnSO}_{4} .7 \mathrm{H}_{2} \mathrm{O}(0.115 \mathrm{~g}, 0.4 \mathrm{mmol})$ in $\mathrm{MeOH}(5 \mathrm{ml})$ were added to a solution of tolfenamic acid $(0.209 \mathrm{~g}, 0.8 \mathrm{mmol})$ in $\mathrm{MeOH}(5 \mathrm{ml})$ separately. Drops of a methanolic solution of $1 \mathrm{~N}$ $\mathrm{NaOH}$ were added to two different solutions until the apparent $\mathrm{pH}$ value was $\sim 7$. The two mixtures were stirred at room temperature for 1 hour and cooled to $5^{\circ} \mathrm{Cin}$ a refrigerator for 4 hours. After the addition of a few drops of distilled $\mathrm{H}_{2} \mathrm{O}$, a pale pink powder and a light yellow powder were precipitated respectively. The two precipitates were collected by filtration and recrystallized from hot $\mathrm{MeOH}$. The powders were washed with cold $\mathrm{MeOH}: \mathrm{H}_{2} \mathrm{O}(5: 1)$ and dried in vacuum to afford $\left[\mathrm{Co}(\text { tolf })_{2}\left(\mathrm{H}_{2} \mathrm{O}\right)_{2}\right]$ and $\left[\mathrm{Zn}(\text { tolf })_{2}\left(\mathrm{H}_{2} \mathrm{O}\right)\right]$ respectively. The yield values were $53 \%, 32 \%$ and $15 \%$ of tolfenamic acid complexes with copper, cobalt and zinc, respectively.

Experimental animals. Adult Swiss-albino mice 25-30 g ages of 4-5 week were used as experimental animal. They were housed properly and kept under well controlled temperature with humidity of $60-70 \%$ in the animal house and kept before the test for 5-7 days because of their environmental sensitivity.

Instrumental measurements. FT-IR Spectra were analyzed with FT-IR 8400S Shimadzu, Japan, spectrophotometer within the range $4000-400 \mathrm{~cm}^{-1}$ to determine the functional groups. A Shimadzu ModelUV-1800 spectrophotometer was used to observe UV-Vis spectra of tolfenamic acid and its metal complexes. DSC is a thermo-analytical measurement technique and was performed by DSC-60 WS, 
Shimadzu, Japan furnished with computer and convenient software program. ${ }^{4}$

Peripheral analgesic activity. Peripheral analgesic activity can be evaluated by acetic acidinduced Writhing method. ${ }^{5}$ Acetic acid was administered intra-peritoneally to the experimental animals to create pain sensation. As a result, the animals squirms their body at regular interval out of pain. This squirm or contraction of the body is termed as "writhing". As long as the animals feel pain, they continue to give writhing. Each writhing is counted and taken as an indication of pain sensation. Any substance that has got analgesic activity is supposed to lessen the number of writhing of animals within in a given time frame and with respect to the control group. The writhing inhibition of positive control was taken as standard and compared with test samples and control. As positive control, any standard NSAID drug can be used. In the present study, tolfenamic acid was used as a standard drug. The test was performed by taking samples at doses of $25 \mathrm{mg} / \mathrm{kg}$ body weight. The degree of analgesia or the percentage of inhibition of writhing was calculated by using the following formula:

(Mean of control group - Mean of treated group)/ Mean of control group $\times 100$.

The result of statistical analysis for animal experiment were expressed as mean \pm SEM; $n=5$ considering $95 \%$ confidence level at $\mathrm{p}<0.05$ being considered as significant.

Central analgesic activity. Tail flick assay of animal models was used to determine central analgesic response. ${ }^{6} \mathrm{~A}$ hot wire was applied to mice tail, which acted as pain stimulus. When the stimulus exceeded the threshold, rat showed instant withdrawal of its tail. ${ }^{7}$ In this experiment, test samples and saline were administrated orally. Tail flicking time was taken by analgesiometer (Medicraft-India). For making the wire hot, current was passed through the wire. The animals flick the tail aside. The time of withdrawal of the tail was recorded. Percentage of time elongation was calculated using the following formula:
$\%$ elongation of reaction time $=($ Average reaction time of test group - Average reaction time of control group)/ Average reaction time of control group.

The central analgesic activity of the test samples were compared in respect to morphine. Statistical analysis was done using Statistical Package for Social Science (SPSS) software by one-way ANOVA considering $95 \%$ confidence level at $\mathrm{p}<0.05$ being considered as significant.

Statistical analysis. Statistical analyses were done by using the Statistical Package for Social Science version (SPSS)16.0 software, and statistical differences between groups were analyzed by oneway analysis of variance ANOVA followed by Dunnet t-tests. Data's were represented as means \pm SEM and differences were considered statistically significant at $\mathrm{p}<0.05$.

\section{RESULTS AND DISCUSSION}

An entrenched method which was slightly modified to prepare the metal complexes of tolfenamic acid was followed which was more economical. ${ }^{8}$ The metal complexes of tolfenamic acid were characterized by both spectral and physicochemical analysis.

FTIR. From the IR spectra of the synthesized metal complexes showed a characteristic bands of absorption by which they were identified. ${ }^{9}$ As the carboxyl $\mathrm{H}$-atom is more acidic than the amino $\mathrm{H}$ atom the deprotonation occurs in the $\mathrm{COOH}$ group. This is confirmed by the IR spectra of the complexes, showing the characteristic bands for the secondary amino groups and for the coordinated carboxylate group. A broad absorption at $3600-3400 \mathrm{~cm}^{-1}$ in the spectra of the complexes was attributed to the presence of coordinated $\mathrm{H}_{2} \mathrm{O}$ shown if table 1.The absence of large systematic shifts of the NH bands (in the region of $3360-3310 \mathrm{~cm}^{-1}$ due to N-H stretch \& $1550-1450 \mathrm{~cm}^{-1}$ due to N-H bend) in the spectra of the complexes compared with those of the ligand tolfenamic acid indicates that there is no interaction between the $\mathrm{NH}$ group and the metal ions. The corresponding bands of $\mathrm{C}=\mathrm{O}$ conjugation of the carboxyl group of the prepared complexes are at 
$1615-1580 \mathrm{~cm}^{-1}$. When compared with that of the ligand tolfenamic acid, it is found that there are significant differences in the frequency of the complexes \& ligands which indicate the formation of metal complex with ligand tolfenamic acid which are presented in figure 1.

Table 1. Assignment of the bands of tolfenamic acid and its metal complexes.

\begin{tabular}{lcl}
\hline Compounds & $\begin{array}{r}\text { Frequency } \\
\left(\mathrm{cm}^{-1}\right)\end{array}$ & Tentative assignment \\
\hline $\mathrm{T}$ & 3339 & $\mathrm{~N}-\mathrm{H}$ stretch of secondary amine \\
& 1499 & $\mathrm{~N}-\mathrm{H}$ bend of secondary amine \\
& 1566 & $\mathrm{C}=\mathrm{O}$ conjugation of $-\mathrm{COOH}$ \\
$\mathrm{T}-\mathrm{Cu}$ & 3400 & Coordinated $\mathrm{H}_{2} \mathrm{O}$ \\
& 3340 & $\mathrm{~N}-\mathrm{H}$ stretch of secondary amine \\
& 1500 & $\mathrm{~N}-\mathrm{H}$ bend of secondary amine \\
& 1581 & $\mathrm{C}=\mathrm{O}$ conjugation of $-\mathrm{COOH}$ \\
$\mathrm{T}-\mathrm{Co}$ & 3624 & $\mathrm{Coordinated} \mathrm{H}_{2} \mathrm{O}$ \\
& 3324 & $\mathrm{~N}-\mathrm{H}$ stretch of secondary amine \\
& 1494 & $\mathrm{~N}-\mathrm{H}$ bend of secondary amine \\
& 1578,1607 & $\mathrm{C}=\mathrm{O}$ conjugation of $-\mathrm{COOH}$ \\
T- $\mathrm{Zn}$ & 3409,3508 & Coordinated $\mathrm{H}_{2} \mathrm{O}$ \\
& 3337 & N-H stretch of secondary amine \\
& 1461 & N-H bend of secondary amine \\
& 1582,1614 & $\mathrm{C}=\mathrm{O}$ conjugation of $-\mathrm{COOH}$ \\
\hline
\end{tabular}

(T: Tolfenamic acid, T-Cu: Copper complex of Tolfenamic acid, T-Co: Cobalt complex of Tolfenamic acid, T-Zn: Zinc complex of Tolfenamic acid)
Table 2. UV-visible spectrometric data of tolfenamic acid and its metal complexes.

\begin{tabular}{lcc}
\hline Compound & $\lambda_{\max }$ & Absorbance \\
\hline $\mathrm{T}$ & 287 & 1.208 \\
$\mathrm{~T}-\mathrm{Cu}$ & 287 & 0.331 \\
$\mathrm{~T}-\mathrm{Co}$ & 287 & 0.181 \\
$\mathrm{~T}-\mathrm{Zn}$ & 287 & 0.043 \\
\hline
\end{tabular}

(T: Tolfenamic acid, T-Cu: Copper complex of Tolfenamic acid, T-Co: Cobalt complex of Tolfenamic acid, T-Zn: Zinc complex of Tolfenamic acid).

UV. Tolfenamic acid and its metal complexes were mixed in chloroform solution and UV-visible light was introduced set at $200-400 \mathrm{~nm}$ range to observe characteristic absorbance. By observing the ultraviolet spectra of tolfenamic acid and its metal complexes revealed that there was clear hypochromic shift given in figure 2. The respective absorbance of tolfenamic acid and its complexes are shown in table 2. All three metal complexes ( $\mathrm{Cu}, \mathrm{Co}$ and $\mathrm{Zn})$ showed hypsochromic shift from parent tolfenamic acid. Tolfenamic acid and its complexes showed peaks of different intensity in the same wavelength, which supported the formation of complexes.

DSC. DSC is an established method for the analysis of synthetic drugs. There was a detectable change in the melting point of the complexes of tolfenamic acid compared with parent tolfenamic

Table 3. Peripheral analgesic activity of tolfenamic acid and its metal complexes.

\begin{tabular}{lccc}
\hline Groups & Dose (mg/kg b.w.) & Number of writhing & \% of Inhibition of writhing \\
\hline Control & - & $76.5 \pm 15.87$ & - \\
Standard(Tolfenamic acid) & 25 & $41 \pm 9.12^{* *}$ & 46.41 \\
Tolfenamic acid-Copper & 25 & $38.5 \pm 10.98^{* *}$ & 49.67 \\
Tolfenamic acid-Cobalt & 25 & $25 \pm 9.68^{* * *}$ & 67.32 \\
Tolfenamic acid-Zinc & 25 & $21 \pm 7.42^{* * *}$ & 72.55 \\
\hline
\end{tabular}

Number of writhing expressed as the mean \pm SEM. Significant at ${ }^{* * *} \mathrm{p}<0.001,{ }^{* *} \mathrm{p}<0.01,{ }^{*} \mathrm{p}<0.05$ compared to control group.

acid. The characteristic endothermic peak of tolfenamic acid was at $214.59^{\circ} \mathrm{C}$ and completely disappears for all the complexes shown in figure 3 . The sharper peaks at $77.17^{\circ} \mathrm{C}, 80.40^{\circ} \mathrm{C}$ and $59.57^{\circ} \mathrm{C}$ for tolfenamic-Cu, tolfenamic-Co and tolfenamic-Zn correspondingly were probably due to evaporation of water of crystallization. It indicates the gradual change in heat capacity along with evidence of dehydration. The peaks at $200.97^{\circ} \mathrm{C}$, $110.55^{\circ} \mathrm{C}$ and $99.44^{\circ} \mathrm{C}$ for tolfenamic- $\mathrm{Cu}$, tolfenamic-Co and tolfenamic- $\mathrm{Zn}$ complexes, consequently showed the melting point of the metal complexes. Therefore, presence of 
characteristic new endothermic peaks and changes of melting point may be the evidence of complexation.

Peripheral analgesic activity. The peripheral analgesic activities of metal complexes of tolfenamic acid in acetic acid-induced writhing method are given in table 3 . The test was performed by taking samples at doses of $25 \mathrm{mg} / \mathrm{kg}$ body weight. $\mathrm{Cu}$, $\mathrm{Co}$ and $\mathrm{Zn}$ complexes of tolfenamic acid showed significant analgesic activity with percentage of inhibition of acetic acid induced writhing 49.67\% ( $\mathrm{p}<0.01)$, $67.32 \%(\mathrm{p}<0.001)$ and 72.55\% $(\mathrm{p}<0.001)$, respectively compared to the standard tolfenamic acid $(46.41 \%, \mathrm{p}<0.01)$.

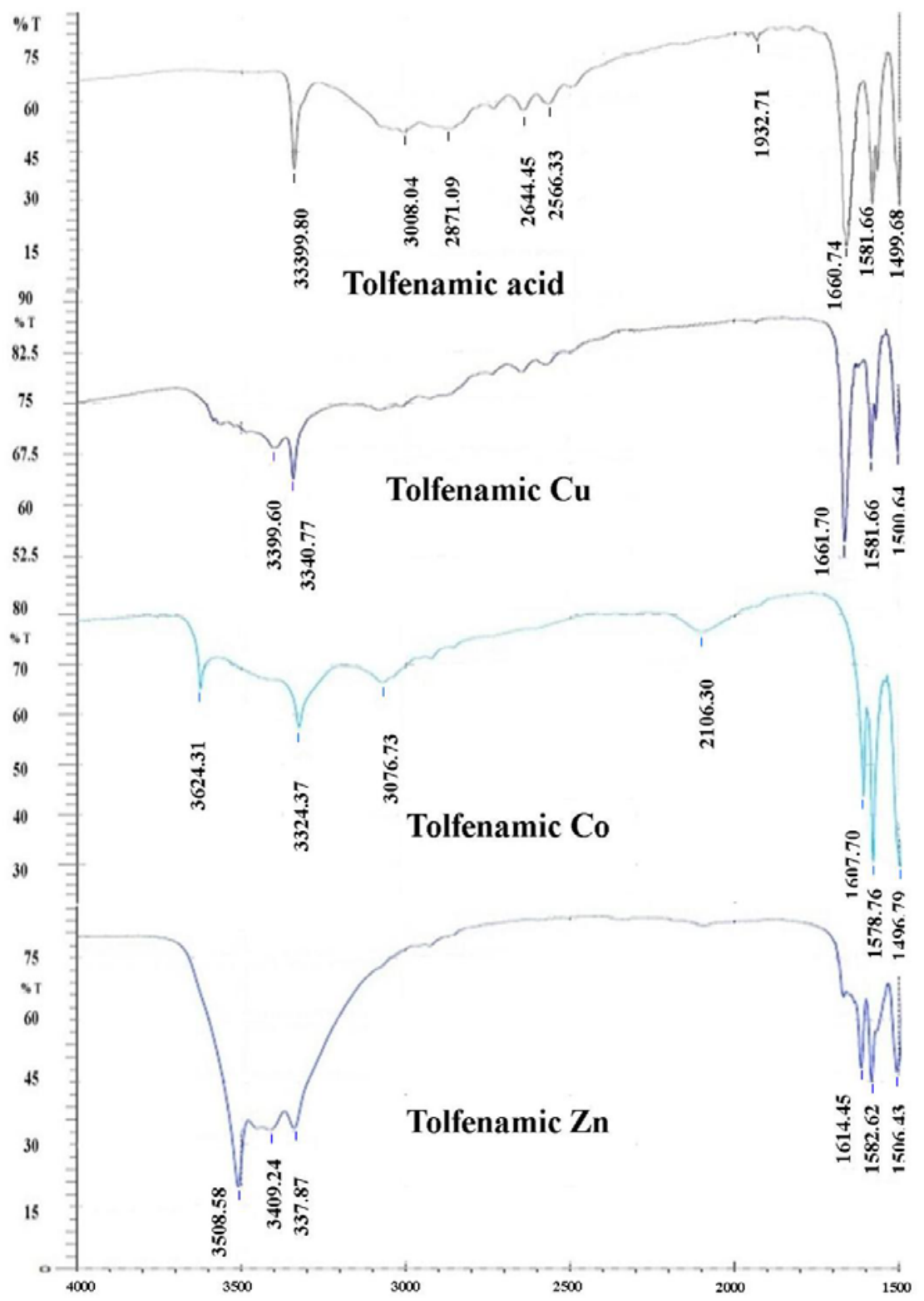

Figure 1. Combined FTIR spectrum of tolfenamic acid and its complexes. 


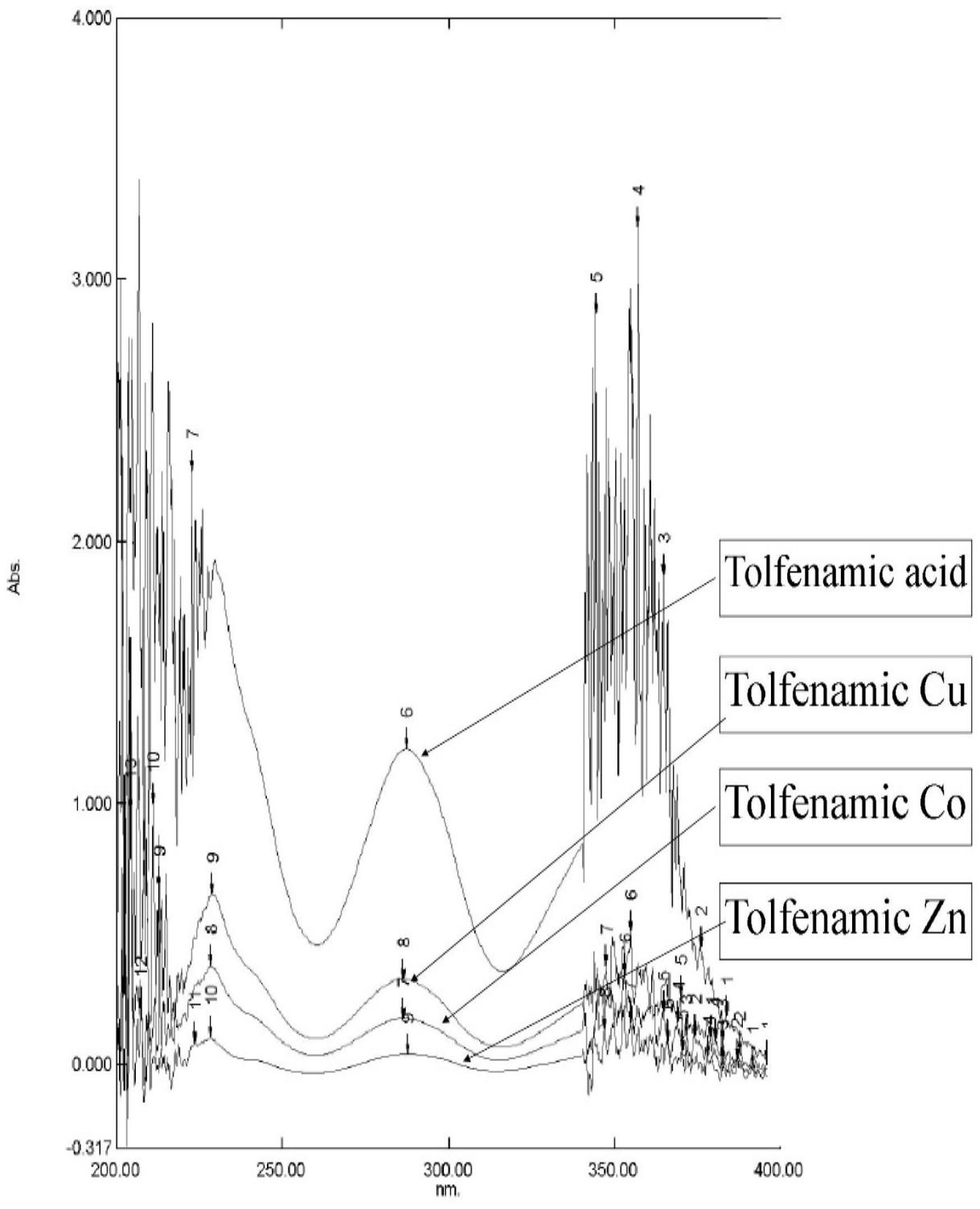

Figure 2. Combined UV- visible spectrum of tolfenamic acid and its complexes.

Table 4. Central analgesic activity of tolfenamic acid and its metal complexes.

\begin{tabular}{lcccc}
\hline & & \multicolumn{3}{c}{ Reaction time $(\mathrm{sec})$} \\
\cline { 3 - 5 } Groups & Dose $(\mathrm{mg} / \mathrm{kg}$ b.w.) & $\begin{array}{c}\text { \% Elongation } \\
\text { (30 min) }\end{array}$ & $\begin{array}{c}\text { \% Elongation } \\
(60 \mathrm{~min})\end{array}$ & $\begin{array}{c}\text { \% Elongation } \\
(90 \mathrm{~min})\end{array}$ \\
\hline Control & & $5.84 \pm 0.44$ & $6.62 \pm 0.20$ & $6.98 \pm 0.20$ \\
Standard & 2 & $15.3 \pm 0.89,161.99^{* * *}$ & $14.08 \pm 0.76,112.69 * * *$ & $11.54 \pm 0.40,65.33^{* * *}$ \\
Tolfenamic acid & 10 & $7.46 \pm 0.49,27.74^{*}$ & $7.08 \pm 0.36,6.95$ & $7.06 \pm 0.21,1.15$ \\
Tolfenamic acid-Copper & 22.9 & $7.86 \pm 0.37,34.59^{* *}$ & $7.24 \pm 0.29,9.37$ & $7.1 \pm 0.31,1.72$ \\
Tolfenamic acid-Cobalt & 23.4 & $7.32 \pm 0.30,25.34^{*}$ & $7.12 \pm 0.22,7.55$ & $7.06 \pm 0.22,1.15$ \\
Tolfenamic acid-Zinc & 23.3 & $8.94 \pm 1.04,53.08^{*}$ & $7.5 \pm 0.63,13.29$ & $7.12 \pm 0.49,2.01$ \\
\hline
\end{tabular}

Each value expressed as the mean \pm SEM. Significant at ${ }^{* * *} \mathrm{p}<0.001,{ }^{* *} \mathrm{p}<0.01,{ }^{*} \mathrm{p}<0.05$ compared to control group. 


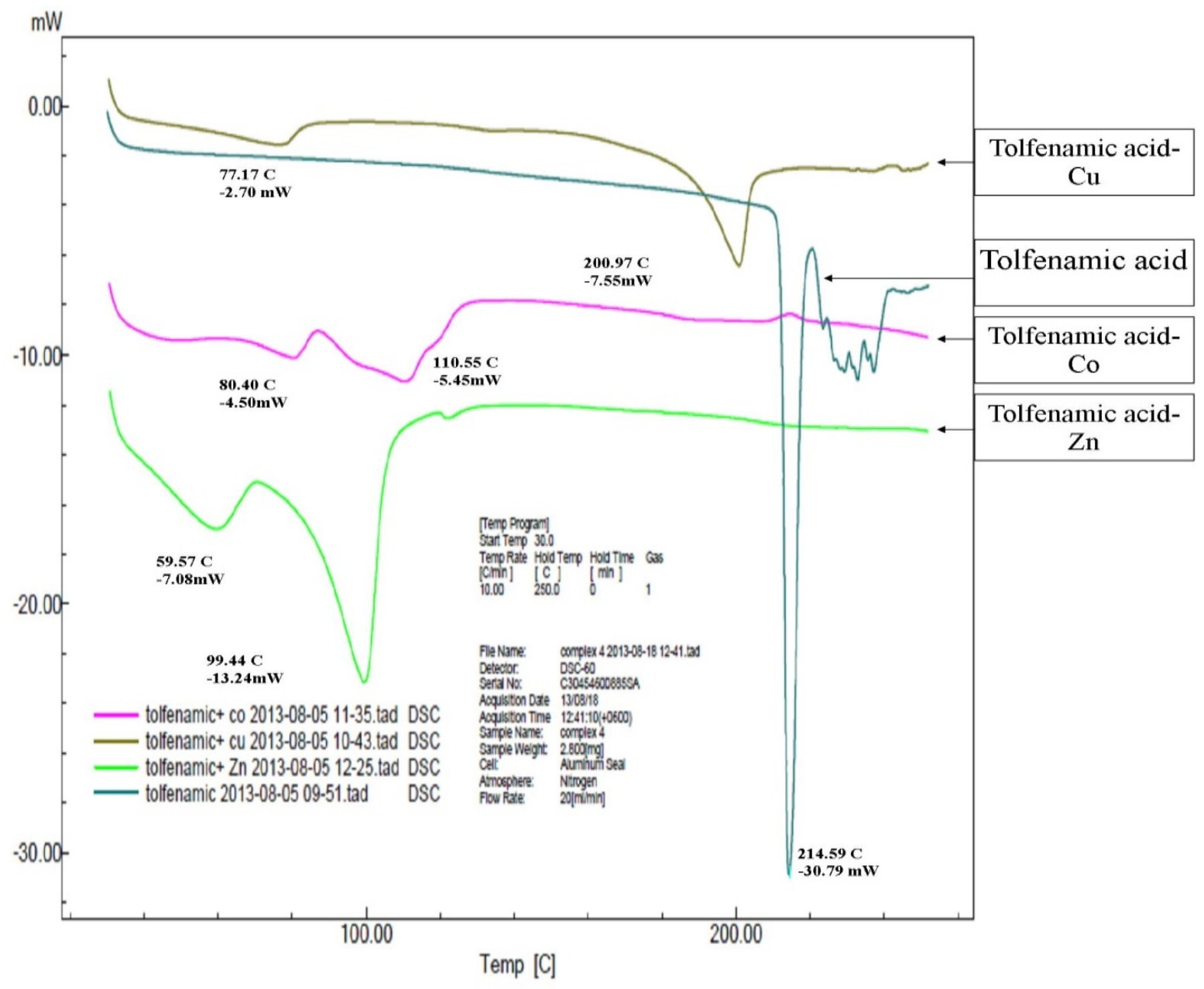

Figure 3. Combined DSC thermogram of tolfenamic acid and its complexes.

Central analgesic activity. The central analgesic activities of metal complexes of tolfenamic acid in tail flick method are given in table 4 . In this experiment, metal complexes were given at an equimolar dose of tolfenamic acid at $10 \mathrm{mg} / \mathrm{kg}$ body weight individually. $\mathrm{Cu}, \mathrm{Co}$ and $\mathrm{Zn}$ complexes of tolfenamic acid (with \% elongation time of $34.59 \%$, $25.34 \%$ and $53.08 \%$, respectively) showed significant analgesic effect compared to that of morphine (2 $\mathrm{mg} / \mathrm{kg}$ body weight) at an equimolar dose of tolfenamic acid at $10 \mathrm{mg} / \mathrm{kg}$ body weight after 30 minutes.

\section{CONCLUSION}

Scanty level of pharmacological investigation on divalent metal complexes of tolfenamic acid was a key driver to design our study and to search for new pharmacological properties such as peripheral and central analgesic potency; to prepare new compounds, i.e., complexes of tolfenamic acid with essential metal ions, which probably would exhibit improved or different biological properties compared to the parent NSAID. The Co and $\mathrm{Zn}$ complexes of tolfenamic acid possess considerably better analgesic potency than the parent tolfenamic acid and further bioactivity guided investigation can lead to the development of new classes of analgesic drugs.

\section{ACKNOWLEDGEMENT}

The authors wish to thank Center for Advance Research in Sciences (CARS), University of Dhaka for providing their support to our research work. 


\section{REFERENCES}

1. Simon, L.S. 2005. The COX -2 inhibitors: a reasoned review of the data. Swiss. Med. Wkly. 135, 419-424.

2. Kay, P. 2000. In vitro effects of nonsteroidal antiinflammatory drugs on cyclooxygenase activity in dogs. Am. J. Vet. Res. 61, 802-810.

3. Shazia, R. 2010. Transition metal complexes as potential therapeutic agents. Biotech. Mol. Bio. Rev. 5, 38-45.

4. Sangita, P.K., Amjad, F.M., Sultana, S., Sultan, M.Z., Hossain, M.A. and Amran, M.S. 2012. Study of differential scanning calorimetry of complex of magnesium sulfate with aspirin, paracetamol and naproxen. Bangladesh Pharm. J. 15, 7-12.

5. Koster, R. 1959. Anderson M and de Beer EJ. 1959. Acetic acid for analgesic screening. Fed. Proc. 18, 412-418.

6. Pizziketti, R.J., Pressman, N.S., Geller, E.B., Cowan, A. and Adler, M.W. 1985. Rat cold water tail-flick: a novel analgesic test that distinguishes opioid agonists from mixed agonist- antagonists. Eur. J. Pharmacol. 119, 23-29.
7. Ahmed, F., Selim, M.S.T., Das, A.K. and Choudhuri, M.S.K. 2004. Anti-inflammatory and antinociceptive activities of Lippia nodiflora Linn. Pharmazie 59, 329-330.

8. Demertzi, D.K., Litina, D.H., Primikiria, A., Staninskaa, M., Kotogloua, C. and Demertzisa, M.A. 2009. Anti-Inflammatory, antiproliferative, and radical-scavenging activities of tolfenamic acid and its metal complexes. Chem. Biodivers. 6, 948-960.

9. Kulaksizoğlu, S., Gökçe, C. and Gup, R. 2012. Asymmetric bis (bidentate) azine ligand and transition metal complexes: synthesis, characterization, DNAbinding and cleavage studies and extraction properties for selected metals and dichromate anions. J. Chil. Chem. Soc. 3, 213-218. 